\title{
Comparison and Correlation between Ultrasonography and Radiography in Skeletal Age Assessment of Children Less than Six Years of Age, based on Greulich \& Pyle Atlas Method
}

\author{
M Dinesh ${ }^{1}$, Gurubharath llangovan ${ }^{2}$, Pooja Varwatte ${ }^{3}$, Harshavardhan Balganesan $^{4}$, Anith Alfred $^{5}$, Pavithra $^{6}$ \\ ${ }^{1}$ Assistant Professor, Department of Radiodiagnosis, SSSMCRI, ${ }^{2}$ Professor and HOD, Department of Radiodiagnosis, SSSMCRI, \\ ${ }^{3}$ Junior Resident, Department of Radiodiagnosis, SSSMCRI, ${ }^{4}$ Senior resident, Department of Radiodiagnosis, SSSMCRI, ${ }^{5}$ Senior \\ Resident, Department of Radiodiagnosis, SSSMCRI, ${ }^{6}$ Senior Resident, Department of Radiodiagnosis, SSSMCRI, Chennai, \\ Tamilnadu, India
}

Corresponding author: Gurubharath Ilangovan, 100 A/5, 11th Sector, 66th Street, Ponnambalam Salai KK Nagar, Chennai, India

DOI: http://dx.doi.org/10.21276/ijcmsr.2019.4.4.5

How to cite this article: M Dinesh, Gurubharath llangovan, Pooja Varwatte, Harshavardhan Balganesan, Anith Alfred, Pavithra A. Comparison and correlation between ultrasonography and radiography in skeletal age assessment of children less than six years of age, based on greulich \& pyle atlas method. International Journal of Contemporary Medicine Surgery and Radiology. 2019;4(4):D19-D25.

\section{A B S T R A C T}

Introduction: Skeletal maturity estimation or Bone Age estimation is a common Radiological procedure which is used in determining the skeletal age of children and young adults indicative of their biological maturity which can then be compared with the Chronological Age. Aims and Objectives: The principal objective of this study was to evaluate Ultrasonography as an alternative to Radiography in determining Bone Age based on Greulich-Pyle Atlas method for Children aged below 6 years and to correlate the estimations and results of both the methods using Altman and Bland Statistical Methods for evaluation of agreement.

Material and Methods: We determined the bone age of 90 children of both genders by two independent methods involving Ultrasonography and Radiography respectively, of the left hand and compared them for agreement using Altman and Bland Plot.

Results: From the results of the Statistical Analysis, we were able to demonstrate that Bone Age estimated using Ultrasonography compared favourably and correlated significantly well $(r=.993)$ with the traditional Radiograph based method.

Conclusion: Bone Age Estimation by Ultrasonography is effective in predicting the skeletal age of the patient. The Bone Age estimated by Ultrasonography was in statistically significant concordance and agreement with the age determined from Radiographs using Greulich and Pyle Atlas method.

Keywords: Bone Age Measurement, Diagnostic X-Ray Radiology, Ultrasonic Diagnosis, Wrist

\section{INTRODUCTION}

Skeletal or Biological age, also termed 'Developmental age' and 'Physiological age,' reflects the level of maturity achieved by the individual. ${ }^{1}$ Skeletal maturity estimation or Bone Age estimation is a common Radiological procedure which is used in determining the skeletal age of children and young adults indicative of their biological maturity which can then be compared with the Chronological Age. The most common method of evaluation uses the standards of Greulich and Pyle as published in their eponymous Atlas for comparison with the left hand radiograph of a patient or subject. Since radiography exposes young children to higher risk of radiation induced cancers and other adverse effects, concerns have been raised and advocacy for minimizing such exposures have been expounded to restrict radiography to essential and evidence based radiology justified diagnostic procedures. The authors of this study are of the opinion that radiography for the sole purpose of bone age determination does not adequately qualify the above criteria. Therefore this study was conceived and executed to evaluate ultrasonography as an alternative imaging modality to radiography in assessing bone age according the Greulich Pyle Atlas method.

Greulich and Pyle (GP) method

This method involves a complex comparison of 28 bones of the hand with the Atlas and selection of the closest match to the atlas radiograph. It is a highly subjective approach. ${ }^{2}$ The growth points that are observed in this method are shown in Figure1. 


\section{MATERIAL AND METHODS}

We determined the bone age of 90 children of both genders by two independent methods involving ultrasonography and radiography respectively, of the left hand and compared them for agreement using Altman and Bland Plot. For the ultrasound method, we formulated a standard operating procedure and protocol for imaging a set criterion of bony structures using ultrasonography and for determining the bone age based on the imaging. For the X-Ray method, we followed standard left hand radiography based method for determining bone age as done traditionally and reported in the literature. Subsequently, each participant underwent an ultrasound examination of the left hand on the same/next day.

The bone age was determined independently and was statistically analysed for Pearson Correlation and BlandAltman Plot for Agreement.

We excluded all children with documented or $\mathrm{x}$-rays indicating a disease process involving the hands or with diseases definitely known to delay or accelerate skeletal maturation.

\section{Standard operating procedures}

The child is requested to extend its left arm in a supinated position and the hand with exposed palm is held gently and supported by the Investigator's left hand. With the probe on the Investigator's right hand, the left hand is imaged steadily with minimum discomfort to the child.

\section{Imaging Technique SOP}

The Probe is held with the right hand in axial or transverse view and placed perpendicular to the axis of the long bones on the wrist of the baby (Figure 2).

The right side of the probe is placed and maintained towards the radial side of the hand for major part of the examination - The RR Rule (Right always towards Radius). Initially, a general survey in axial section is carried out on the proffered wrist region of the subject's hand. The total number of bony structures visualised including carpals and epiphyses are counted and summed.

The sum of the structures should correspond to subject's age and gender.

The radius and ulna, being prominent structures are imaged by sagittal view and with their orientation, the First Metacarpal Epiphysis is visualised next.

The width of (1) 1st metacarpal's epiphysis and (2) the width of the 1st metacarpal's shaft measured adjacent to the epiphysis are measured in axial view and their ratio established. Similar method is adopted for the 3, 4 and 5 th distal phalanges.

The Carpal bones are accessed as proximal row (Figure 3) and distal row (Figure 4) bones.

The total number of bony structures counted earlier is subtracted from the epiphyses to obtain the number of carpal bones in the wrist region.

\section{Assessment criterion as per Greulich-pyle atlas}

Although in the Greulich-Pyle Atlas, about 28 bones are assessed, we have, for brevity, chosen to take into consideration only 14 bony structures for assessment (Table
1) and key structures in BOYS and GIRLS assessed for determining the Bone Age based on the Greulich Pyle atlas shown in (Table 2).

Measurement of Diameters of Epiphyses: When measuring the ratio of the epiphyseal diameter and the diameter of its adjacent shaft, linear measurements are plotted closest and adjacent to the epiphysis since the shaft narrows down towards the midshaft. The width of the third, fourth and fifth phalangeal shafts are measurable for female children by 5 yrs. of age.

When the arm is pronated and imaged dorsally, care should be taken for adhering to the RR Rule. The supinated position is always better for visualisation and can be standardised since it is comfortable for the patient who can maintain the position till completion of the scan.

Bone age assessment: $A$ patient's bone age was assessed by comparing the maturity indicators on the patient's X-Ray or USG scan to the standardized reference atlas according to the Greulich and Pyle method.

\section{STATISTICAL ANALYSIS}

To assess the agreement of measured values, i.e. Age in months between two methods namely, (1) Bone Age estimation by ultrasonography based on Greulich Pyle Atlas (2) Bone Age estimation by radiography based on Greulich Pyle Atlas, we used the methods described by Bland and Altman - the Bland-Altman Plot.

\section{Bland - Altman Plot}

It is used to describe agreement between two quantitative measurements. ${ }^{3}$ There's no p-value available to describe this agreement but rather a "quality control" concept. The difference of the paired two measurements is plotted against the mean of the two measurements and they recommend that $95 \%$ of the data points should lie within the $\pm 2 \mathrm{SD}$ of the mean difference.

We subjected the Greulich-Pyle Atlas based age assessments done independently using radiographs and by ultrasonography to Altman and Band statistical analysis to assess the degree of agreement, correlation and concordance between the two methods and the results along with the Bland-Altman chart are depicted below in the Results.

\section{RESULTS}

From the results of the statistical analysis, we were able to demonstrate that Bone Age estimated using Ultrasonography compared favourably and correlated significantly well $(\mathrm{r}=.993)$ with the traditional radiograph based method. Further, ultrasonographical examination was easier, quicker and involved less discomfort as well as substantial risk reduction in terms of exposure to ionising radiation for the young children. Altman and Bland plot revealed significant degree of agreement between the two methods with $95 \%$ of the measurements lying close to the mean and well between 2 standard deviations.

Descriptive statistics for Girls and Boys is as shown in Table 3. The ages estimated by both USG and X-ray methods also followed normal distribution. (Graph1, Graph2). 


\begin{tabular}{|c|c|c|}
\hline \multicolumn{3}{|c|}{14 Bony structures included in our study for bone age assessment } \\
\hline \multirow{13}{*}{ (מָน } & Capitate & 1 \\
\hline & Hamate & 1 \\
\hline & Distal epiphysis of Radius & 1 \\
\hline & Epiphysis of proximal phalanx of 5th Finger & 1 \\
\hline & Triquetral & 1 \\
\hline & Lunate & 1 \\
\hline & Trapezium & 1 \\
\hline & Epiphysis of $1^{\text {st }}$ Metacarpal & 1 \\
\hline & Trapezoid & 1 \\
\hline & Scaphoid & 1 \\
\hline & Epiphysis of distal phalanx of 3,4 and 5th Fingers & 3 \\
\hline & Distal epiphysis of Ulna & 1 \\
\hline & Total & 14 \\
\hline
\end{tabular}

\begin{tabular}{|c|c|c|}
\hline & Boys & Girls \\
\hline At Birth & \multicolumn{2}{|l|}{ No Carpal Bones seen } \\
\hline 3 Months & $\begin{array}{l}\text { Ossification centre of Capitate and Hamate bones } \\
\text { visible }\end{array}$ & $\begin{array}{l}\text { Ossification centre of Capitate and Hamate bones } \\
\text { visible }\end{array}$ \\
\hline 1 Year & & Distal epiphysis of the radius can be visualised \\
\hline 1 Year 3 Months & Distal epiphysis of the radius can be visualised & \\
\hline 1 Year 6 Months & & $\begin{array}{l}\text { Epiphysis of Proximal phalanx of 5th finger is } \\
\text { visualised }\end{array}$ \\
\hline 2 Years & $\begin{array}{l}\text { Epiphysis of Proximal phalanx of 5th finger is } \\
\text { visualised }\end{array}$ & Ossification centre is visible in Triquetral bone \\
\hline 2 Years 8 Months & Ossification centre of Triquetral bone is visible & \\
\hline 3 Years & \multicolumn{2}{|l|}{ Ossification centre of Lunate bone is visible } \\
\hline 3 Years 6 Months & $\begin{array}{l}\text { Epiphysis of Distal Phalanx of 3, } 4 \text { and 5th Finger } \\
\text { visible }\end{array}$ & $\begin{array}{l}\text { Diameter of Epiphysis of 1st Metacarpal Bone is more } \\
\text { than half of its adjacent Shaft } \\
\text { Ossification centre of Trapezium bone is visible }\end{array}$ \\
\hline 4 Years & Ossification centre of Trapezium bone is visible & \\
\hline 4 Years 2 Months & & Ossification centre of Trapezoid and Scaphoid is visible \\
\hline 5 Years & $\begin{array}{l}\text { Diameter of Epiphysis of 1st Metacarpal Bone is more } \\
\text { than half of its adjacent Shaft }\end{array}$ & $\begin{array}{l}\text { Epiphysis of Distal Phalanx of 3, } 4 \text { and 5th Fingers are } \\
\text { as Wide as their Shaft in Diameter }\end{array}$ \\
\hline 6 Years & $\begin{array}{l}\text { Ossification centre of Trapezoid and Scaphoid is visible } \\
\text { Epiphysis of Distal Ulna is visible }\end{array}$ & Epiphysis of Distal Ulna is visible \\
\hline
\end{tabular}

\begin{tabular}{|c|c|c|c|c|c|c|}
\hline \multicolumn{2}{|c|}{ Gender } & \multirow{2}{*}{$\frac{\mathbf{N}}{37}$} & \multirow{2}{*}{$\begin{array}{c}\text { Minimum } \\
13.00\end{array}$} & \multirow{2}{*}{$\begin{array}{c}\text { Maximum } \\
81.00\end{array}$} & \multirow{2}{*}{$\begin{array}{c}\text { Mean } \\
44.5135\end{array}$} & \multirow{2}{*}{$\begin{array}{c}\text { Std. Deviation } \\
16.64269\end{array}$} \\
\hline Girls & Age in Months & & & & & \\
\hline & USG Estimated Age (months) & 37 & 12.00 & 72.00 & 38.1081 & 15.61300 \\
\hline & Radiograph Estimated Age (months) & 37 & 12.00 & 72.00 & 38.7027 & 15.83397 \\
\hline & Weight (kg) & 37 & 7.80 & 24.00 & 14.2838 & 3.43661 \\
\hline & Height $(\mathrm{cm})$ & 37 & 68.00 & 108.60 & 93.5324 & 10.89368 \\
\hline & Valid N (listwise) & 37 & & & & \\
\hline \multirow[t]{6}{*}{ Boys } & Age in Months & 53 & 4.00 & 79.00 & 39.9434 & 21.54192 \\
\hline & USG Estimated Age (months) & 53 & 3.00 & 72.00 & 34.3396 & 19.52606 \\
\hline & Radiograph Estimated Age (months) & 53 & 3.00 & 72.00 & 34.9623 & 20.21801 \\
\hline & Weight (kg) & 53 & .60 & 22.00 & 13.4283 & 4.32277 \\
\hline & Height $(\mathrm{cm})$ & 53 & 59.60 & 113.80 & 90.0226 & 14.13968 \\
\hline & Valid N (listwise) & 53 & & & & \\
\hline & & escr & atistics for & d Boys & & \\
\hline
\end{tabular}

\section{Correlation analysis}

Test of association between ultrasonographically estimated bone age and radiography determined bone age was carried out using Pearson Correlation analysis (Table 4).

We were able to detect significant correlation $(r=.993)$, from our sample of 90 analysable subjects with $95 \%$ power 


\begin{tabular}{|c|c|c|c|c|}
\hline & & $\begin{array}{l}\text { USG Estimated } \\
\text { Age (months) }\end{array}$ & $\begin{array}{c}\text { Radiograph } \\
\text { Estimated Age (months) }\end{array}$ & $\begin{array}{l}\text { Chronological } \\
\text { Age (months) }\end{array}$ \\
\hline \multirow[t]{3}{*}{ USG Estimated Age (months) } & Pearson Correlation & 1 & $.993^{* *}$ & $.971^{* *}$ \\
\hline & Sig. (2-tailed) & & .000 & .000 \\
\hline & $\mathrm{N}$ & 90 & 90 & 90 \\
\hline \multirow[t]{3}{*}{ Radiograph Estimated Age (months) } & Pearson Correlation & $.993^{* *}$ & 1 & $.973^{* *}$ \\
\hline & Sig. (2-tailed) & .000 & & .000 \\
\hline & $\mathrm{N}$ & 90 & 90 & 90 \\
\hline \multirow[t]{3}{*}{ Chronological Age (months) } & Pearson Correlation & $.971^{* *}$ & $.973^{* *}$ & 1 \\
\hline & Sig. (2-tailed) & .000 & .000 & \\
\hline & $\mathrm{N}$ & 90 & 90 & 90 \\
\hline
\end{tabular}
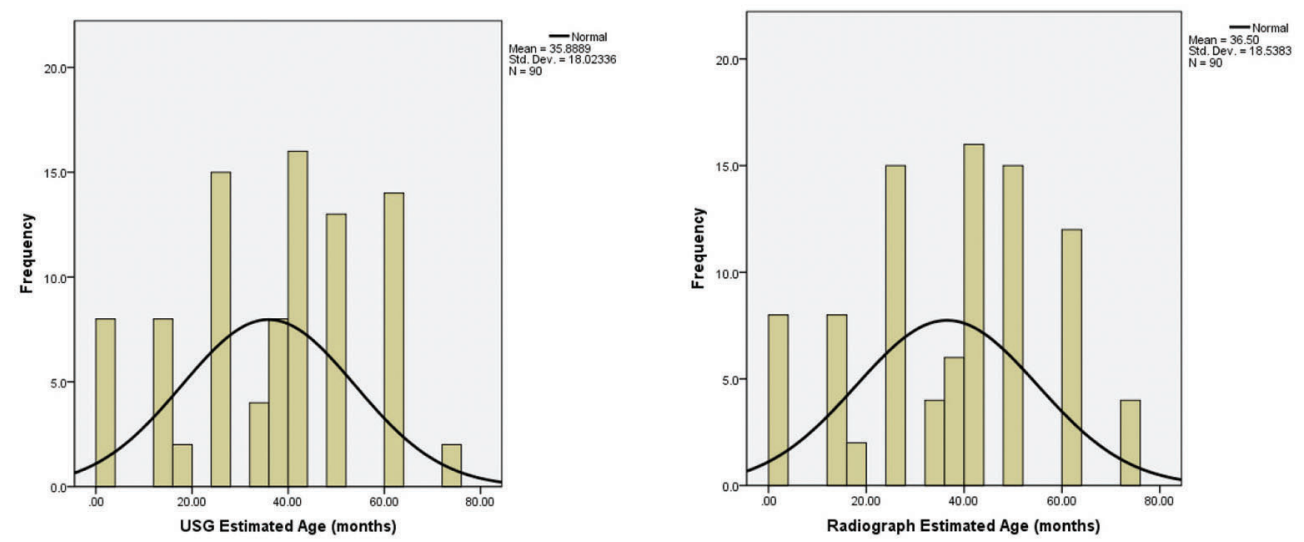

Graph-1 and 2: The Ages estimated by both USG and X-Ray methods also followed normal distribution.

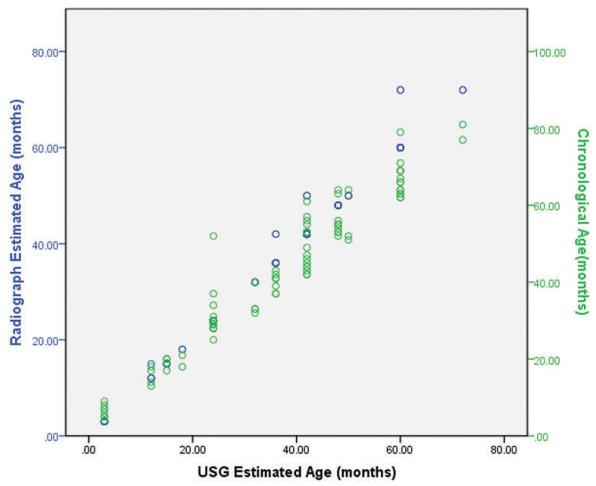

Graph-3: shows correlation between USG \& Radiography assessed Bone Age with the line of equality.

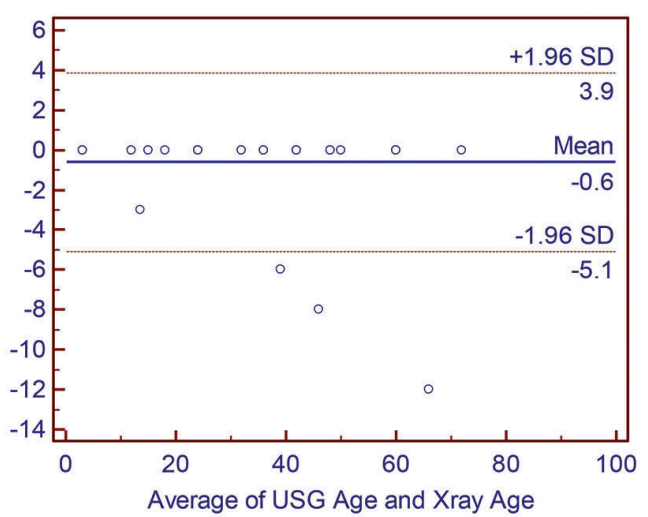

Graph-4: Shows - Bland and Altman plot of the variation between Radiography and Ultrasonography assessments.

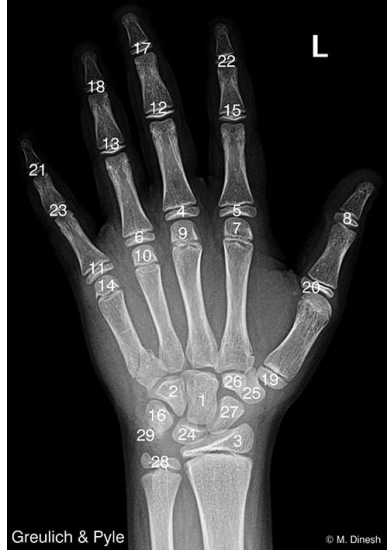

Figure-1: In the Order referenced in the GP Atlas: Capitate(1), Hamate(2), Distal Epiphysis of the Radius(3), Epiphysis of Proximal Phalanx of Digit Third, Second, Fourth $(4,5,6$,$) , Epiphysis of the Second Metacarpal (7), Epiphysis$ of the Distal Phalanx of First Digit(8), Epiphysis of the Third, Fourth And Fifth Metacarpals $(9,10,14)$, Epiphysis of the Proximal Phalanx of the Fifth Digit (11), Epiphysis of the Middle Phalanx of the Third Second, And Fourth Digit $(12,13,15)$, Triquetral(16), Epiphysis of the Distal Phalanx of the Third And Fourth Digit $(17,18)$, Epiphysis of the First Metacarpal (19), Epiphysis of the Proximal Phalanx of the First Digit (20), Epiphysis of Distal Phalanx of the Fifth And Second Digit(21,22),Epiphysis of Middle Phalanx of Fifth Digit (23), Lunate (24), Trapezium(25), Trapezoid(26), Scaphoid (27) Distal Epiphysis of the Ulna (28), Pisiform (29) 


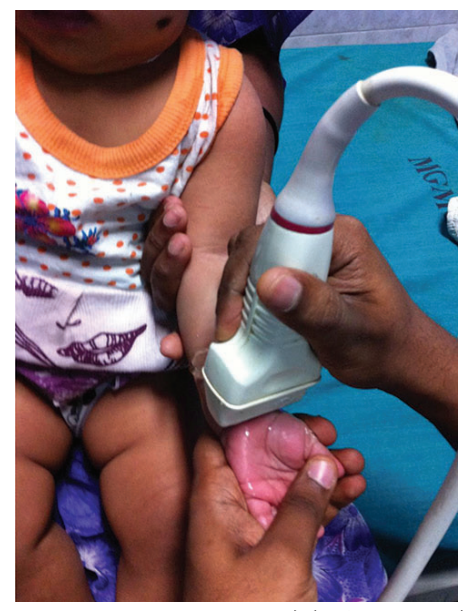

Figure-2: Imaging Technique: The Probe is held with the right hand in axial or transverse view and placed perpendicular to the axis of the long bones on the wrist of the baby.

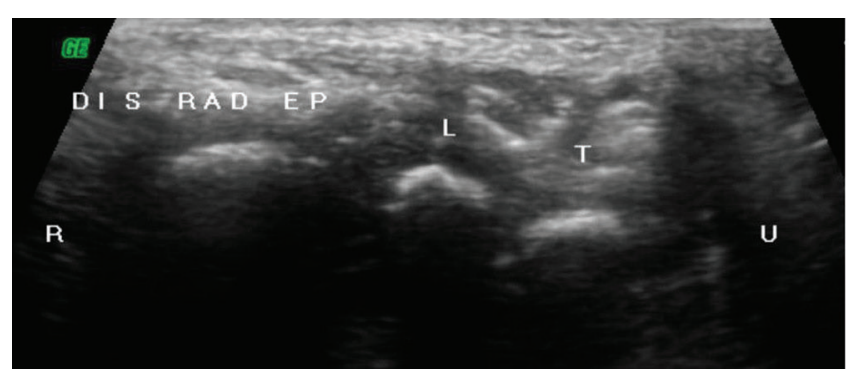

Figure-3: Ultrasound images of carpal bones.

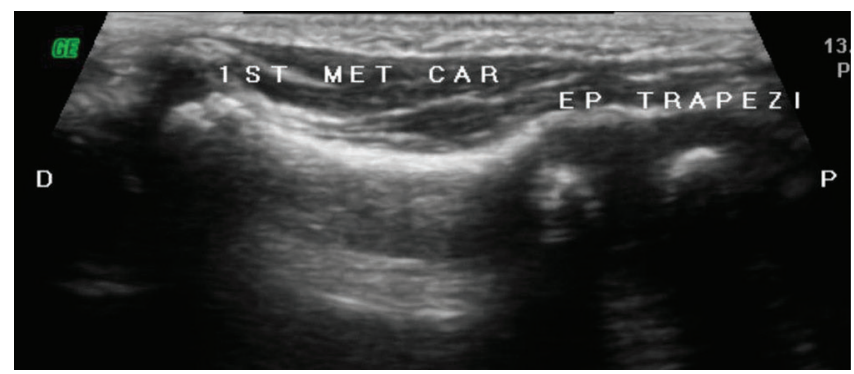

Figure-4: Ultrasound images of Carpal bones.

between the two methods.

The Correlation analysis between Chronological Age and USG estimated age, Radiology estimated age also showed significant correlation at $\mathrm{r}=0.971$ and $\mathrm{r}=0.973$ respectively. The Graph below shows the scatter plot between Ultrasonographically calculated Bone Age vs. Radiologically calculated Bone Age both based on Greulich Pyle Atlas Method, the correlation is 0.993, p<0.001 (Highly significant). Graph 3 shows correlation between USG \& Radiography assessed Bone Age with the line of equality. There was no significant difference between the genders with regard to correlations between USG and X-ray estimated bone age.

\section{Bland Altman analysis}

Bland and Altman plot the mean difference between the X-ray and DXA assessments was -0.6 months with corresponding limits of agreement of 3.9 and $-5.1(2 \mathrm{xSD})$. The mean difference did not significantly differ from zero, indicating lack of systematic differences. Graph 4 shows -
Bland and Altman plot of the variation between Radiography and ultrasonography assessments. The mean indicates the mean difference, with the $95 \%$ limits of agreement.

\section{Deming regression equation}

Deming Regression Analysis of Concordance between the Two Methods gave a statistically significant Concordance Correlation Coefficient of 0.99 and was in line with the values obtained from the Bland Altman Plots.

\begin{tabular}{|l|c|c|c|}
\hline \multicolumn{4}{|l|}{$\mathbf{y}=\mathbf{0 . 2 1 9 9}+\mathbf{1 . 0 0 1 1} \mathrm{x}$} \\
\hline Parameter & Coefficient & Std. Error & $\mathbf{9 5 \%} \mathbf{C l}$ \\
\hline Intercept & 0.2199 & 0.3225 & -0.4209 to 0.8608 \\
\hline Slope & 1.0011 & 0.01060 & 0.9801 to 1.0222 \\
\hline
\end{tabular}

\section{Concordance correlation coefficient}

\begin{tabular}{|l|c|}
\hline Sample size & 90 \\
\hline Concordance correlation coefficient & 0.9964 \\
\hline $95 \%$ Confidence Interval & 0.9946 to 0.9976 \\
\hline Pearson $\rho$ (precision) & 0.993 \\
\hline Bias correction factor $C_{b}$ (accuracy) & 0.9999 \\
\hline
\end{tabular}

\section{DISCUSSION}

Bone Age Estimation is required in radiological practice for two major reasons:

A. To assess and diagnose pediatric endocrinological diseases and growth disorders,

B. For medico-legal reasons.

In the field of Pediatric endocrinology, skeletal maturity measured by Bone Age is not only essential but highly crucial for a number of reasons:

1. For diagnosing underlying cause in short stature children with growth delay.

2. for reassuring young people (and their concerned parents) with non-pathological but unusual growth delay

3. Monitoring growth hormone and anabolic steroid therapy

4. Monitoring treatment in various endocrinopathies, e.g., hypothyroidism, congenital adrenal hyperplasia

5. In the differential diagnosis of sexual precocity

6. For prediction of adult height

7. For selection of children in sports

8. Public health reasons - Comparison of environmental, dietary and other factors between different populations.

One of the most popular methods of skeletal maturity assessment is by the Greulich and Pyle Atlas Method (G-P method). Our aim was not only to find out if the Bone age estimated using Ultrasonography agreed with the Bone age estimated through radiographs, but also to explore, determine and establish a standard operating procedure for the use of Ultrasonography for Bone Age Estimation so that Children could not only be spared the ionizing radiation and its associated hazards, but also to advocate routine Hand-wrist ultrasonographic determination of bone age of Children. ${ }^{5}$ Such routine and periodic assessment of bone age of growing children could help diagnose a number of growth related diseases and initiate prophylactic or therapeutic interventions. . $, 6,7,8,9,10$

In Our study, we estimated the bone ages of 90 children 
aged up to 6 years by two modalities independently: Bone Age Estimation by Ultrasonography of the Hand and Wrist; Bone Age Estimation from Radiograph of the Hand and Wrist.

The Bland and Altman plots, as well as the simple plot of one method against the other, visualised very high agreement between both methods. The mean difference between the methods did not deviate more than $5 \%$ from the mean of both methods, which we defined prior to the study to be the maximum acceptable difference. Our results suggest that both methods assess bone age with a very small difference and that $95 \%$ of all coupled assessments did not differ more than 1 year. ${ }^{7,11-14}$

For bone age assessment alone, use of Radiography cannot be adequately justified, even though it cannot be completely substituted by ultrasonography. The primary thrust and aim of this study was to establish ultrasonography as a viable, cost effective and comparable method to assess the bone age based on Greulich and Pyle Atlas method instead of relying solely on radiographs of hand and wrist $\mathrm{t}^{7,15-20}$

We have adequately established evidence for the need to monitor growth of children, particularly in our country where malnutrition and associated hormonal imbalances is widely prevalent, and the advantages of such screening in diagnosing possible endocrinological and other growth related disorders well in time. In the light of such evidence, it is imperative to consider strongly routine Ultrasonographical bone age assessment for all children regularly in equipped hospitals and should replace Radiographs unless strongly indicated for confirmation and records. ${ }^{7,20,21}$ Such a periodic assessment should form part of routine health check-up clinics for children and incorporated into Social Health Services at least at the Tertiary Care level.

\section{CONCLUSION}

Based on the results and the methodology employed, we have concluded that: Bone Age Estimation by Ultrasonography is effective in predicting the skeletal age of the patient. The Bone Age estimated by Ultrasonography was in statistically significant concordance and agreement with the Age determined from Radiographs using Greulich and Pyle Atlas method. Furthermore, the Ultrasonography method is practical, quick and accessible and can also be used to evaluate underlying endocrinological pathologies as well as repeatable for follow-ups. The Ultrasonographical method of Bone Age Estimation could be employed effectively for routine screening of young children visiting the hospital for periodic Growth evaluation and monitoring. Use of Ultrasonography for growth screening of children is a safe, easy to use and accurate method for diagnosis and monitoring of metabolic, endocrine, nutritional, bone and growth related diseases.

\section{REFERENCES}

1. Todd,T.W., and J.D'Errico,Jr. The Clavicular Epiphyses. American Journal of Anatomy 4:25-50.

2. A. Dimeglio, Y. P. Charles, J. Daures, V. de Rosa, and B. Kabore, "Accuracy of the Sauvegrain Method in determining skeletal age during puberty," Journal of Bone and Joint Surgery 2005;87(8):1689-1696.
3. Bland, J.M., \& Altman, D.G. Statistical methods for assessing agreement between two methods of clinical measurement. Lancet 1986;327(8476):307-310.

4. zShu XO, Potter JD, Linet MS, Severson RK, Han $\mathrm{D}$, Kersey JH, et al. Diagnostic X-rays and ultrasound exposure and risk of childhood acute lymphoblastic leukemia by immunophenotype. Cancer Epidemiol Biomarkers Prev 2002;11(3):177-85.

5. ICRP. The 2007 Recommendations of the International Commission on Radiological Protection. ICRP publication 103. Ann ICRP 2007;37(2):1-332.

6. Jimenez-Castellanos J, Carmona A, Catalina-Herrera CJ, Vinuales M. Skeletal maturation of wrist and hand ossification centers in normal Spanish boys and girls: a study using the Greulich-Pyle method. Acta Anat 1996;155(5):206-11.

7. Greulich W W, Pyle S I, Radiographic atlas of skeletal development of the hand and wrist, 2nd ed. Stanford Calif., Stanford University Press, 1959.

8. Tanner, J M, Whitehouse, R H, Marshall, W A, et al. Assessment of skeletal maturity and prediction of adult height (TW2 method). NY, Academic Press.

9. H. Mentzel, C. Vilser, M. Eulenstein, T. Schwartz, S. Vogt, J. Bottcher, I. Ya-niv, L. Tsoref, E. Kauf, and W. Kaiser. Assessment of skeletal age at the wrist in children with a new ultrasound device. Pediatric Radiology, 2005;35(4):429-433.

10. R. Ashby, I. Hodgkinson, E. Harrison, K. Ward, Z. Mughal, and J. Adams. Bone age assessment by dxa and standard radiographs; comparison with chronological age. Journal of Bone Mineral Research, 17(298), 2002.

11. R. K. Bull, P. D. Edwards, P. M. Kemp, S. Fry, and I. A. Hughes. Bone age assessment: a large scale comparison of the Greulich and Pyle, and Tanner and Whitehouse (TW2) methods. Archives of Disease in Childhood, 1999;81(5):172- 173.

12. Castriota-Scanderbeg, A. et al. Skeletal Age Assessment in Children and Young Adults: Comparison Between a Newly Developed Sonographic Method and Conventional Methods. Skeletal Radiol; 1998;27(3): 271-277.

13. G. R. Milner, R. Levick, and R. Kay. Assessment of bone age: a comparison of the greulich and pyle, and the tanner and whitehouse methods. Clin Radiol., 1986;37(4):119-121.

14. Bayley N, Pinneau SR. Tables for predicting adult height from skeletal age: revised for use with the Greulich-Pyle hand standard. J Pediatr 1952; 40(6):423-441.

15. Wagner UA, Diedrich V, Schmitt O. Determination of skeletal maturity by ultrasound: a preliminary report. Skeletal Radiol 1995; 24(6):417-420.

16. Hall EJ, Giaccia AJ. Radiobiology for the Radiologist. 6th ed. Philadelphia, PA: Lippincott; 2005.

17. UNSCEAR 2000. The United Nations Scientific Committee on the Effects of Atomic Radiation. Health Phys 79:314.

18. National Academy of Sciences (2005) Health risks from exposure to low levels of ionizing radiation: BEIR VII. National Academies Press, Washington DC.

19. ICRP. Publication 90: Biological effects after prenatal irradiation (embryo and fetus). 2003. p. 167-170.

20. Bland JM, Altman DG. Applying the right statistics: 
analyses of measurement studies. Ultrasound Obstet Gynecol 2003;22(6):85-93.

21. S. Aja-Fernandez, R. de Luis-Garcia, M. A. MartinFernandez, and C. Alberola-Lopez. A computational TW3 classifier for skeletal maturity assessment: a computing with words approach. J. of Biomedical Informatics, 2004;37(2):99-107.

Source of Support: Nil; Conflict of Interest: None

Submitted: 15-06-2019; Accepted: 20-09-2019; Published online: 20-10-2019 